\title{
Drug Poisoning Mortality, by State and by Race and Ethnicity: United States, 2019
}

by Arialdi M. Miniño, M.P.H., and Holly Hedegaard, M.D.

In 2019, 70,630 deaths from the toxic effects of drug poisoning (drug overdose) occurred in the United States (1), a 4.8\% increase compared with 2018 and the highest recorded number in recent history. Drug overdose deaths remain a persistent and urgent public health problem in the United States. This NCHS Health E-Stat provides information on drug overdose mortality by state (and the District of Columbia) and by race and ethnicity, and adds to findings from a recently published Data Brief on drug overdose death rates (1).

The age-adjusted rate for drug overdose deaths in the United States for 2019 was 21.6 per 100,000 standard population (Figure 1, Table). The five states with the highest rates were West Virginia (52.8), Delaware (48.0), District of Columbia (43.2), Ohio (38.3), and Maryland (38.2). The five states with the lowest rates were Nebraska (8.7), South Dakota (10.5), Texas (10.8), North Dakota (11.4), and Iowa (11.5).

The age-adjusted drug overdose death rate for the non-Hispanic white population in 2019 (26.2 per 100,000 standard population) was $21.3 \%$ higher than the national rate (Figure 2). The rate for the non-Hispanic black population (24.8) was 14.8\% higher than the national rate. The rate for the non-Hispanic American Indian or Alaska Native population (30.5) was 41.2\% higher than the national rate. The rate for the non-Hispanic Asian population (3.3) was $84.7 \%$ lower than the national rate. The rate for the non-Hispanic Native Hawaiian or Other Pacific Islander population (9.5) was 56.0\% lower than the national rate. The rate for the Hispanic population (12.7) was $41.2 \%$ lower than the national rate.

\section{Data source and methods}

Data are from the National Vital Statistics System Multiple Cause-of-death file for 2019. Deaths and death rates were produced using the Centers for Disease Control and Prevention's WONDER online database (2). Drug overdose deaths were classified using International Statistical Classification of Diseases, 10th Revision underlying cause-of-death codes X40-X44, X60-X64, $\mathrm{X} 85$, and $\mathrm{Y} 10-\mathrm{Y} 14$.

Starting with 2018 data, the National Vital Statistics System has presented mortality statistics by race using the Office of Management and Budget's (OMB) 1997 standards for collecting, tabulating, and reporting race and ethnicity in the United States (3). Estimates for prior years were produced according to the 1977 OMB standards (4). Single-race estimates based on the 1997 OMB standards may not be comparable to estimates for earlier years that were produced by 
bridging multiple-race choices back to a single-race category. This lack of comparability applies particularly to the race categories with smaller populations (5).

Death rates for non-Hispanic Asian or Pacific Islander, non-Hispanic American Indian or Alaska Native, and Hispanic persons may be underestimated and should be interpreted with caution (6).

Age-adjusted death rates were calculated using the direct method and the 2000 U.S. standard population. Vintage 2019 population data were single-race postcensal estimates of the July 1 resident population produced by the U.S. Census Bureau and released on June 25, 2020. The statistical significance of differences between the national rate and those computed for the race and Hispanic-origin populations was assessed using a $z$ test. Any differences mentioned (higher than, lower than) were significant at the 0.05 level. State-specific rates were ranked and classified according to the percentile distribution of all the values. Statistical significance was not assessed to compare the state-specific death rates.

\section{References}

1. Hedegaard H, Miniño AM, Warner M. Drug overdose deaths in the United States, 1999-2019. NCHS Data Brief, no 394. Hyattsville, MD: National Center for Health Statistics. 2020. Available from: https://www.cdc.gov/nchs/products/databriefs/db394.htm.

2. Centers for Disease Control and Prevention. 2018-2019 underlying cause of death by singlerace categories on CDC WONDER. 2020. Available from: https://wonder.cdc.gov/Deaths-byUnderlying-Cause.html.

3. Office of Management and Budget. Revisions to the standards for the classification of federal data on race and ethnicity. Fed Regist 62(210):58782-90. 1997. Available from: https://www.govinfo.gov/content/pkg/FR-1997-10-30/pdf/97-28653.pdf.

4. Office of Management and Budget. Racial and ethnic standards for federal statistics and administrative reporting. Statistical Policy Directive no. 15. 1977. Available from: https://obamawhitehouse.archives.gov/omb/fedreg_directive_15/.

5. Murphy SL, Xu JQ, Kochanek KD, Arias E, Tejada-Vera B. Deaths: Final data for 2018. National Vital Statistics Reports; vol 69 no 13. Hyattsville, MD: National Center for Health Statistics. 2020.

6. Arias E, Heron M, Hakes JK. The validity of race and Hispanic-origin reporting on death certificates in the United States: An update. National Center for Health Statistics. Vital Health Stat 2(172). 2016.

\section{Suggested citation}

Miniño AM, Hedegaard H. Drug poisoning mortality, by state and by race and ethnicity: United States, 2019. NCHS Health E-Stats. 2021. DOI: https://doi.org/10.15620/cdc:103967. 
Figure 1. Age-adjusted drug overdose death rates, by state: United States, 2019

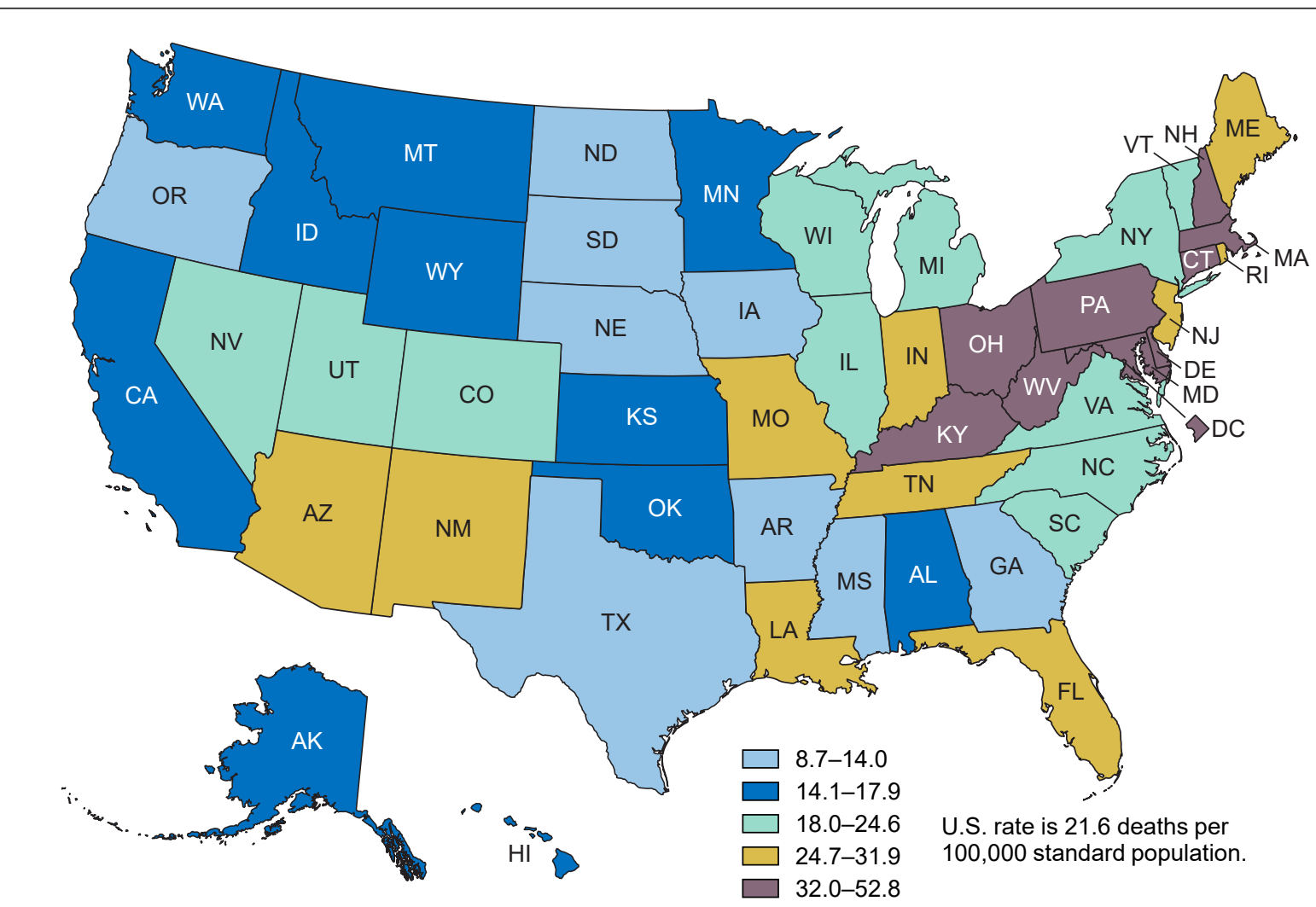

NOTES: Drug overdose deaths were identified using International Classification of Diseases, 10th Revision underlying cause-of-death codes X40-X44, X60-X64, X85, and Y10-Y14. Age-adjusted death rates were calculated using the direct method and the 2000 U.S. standard population.

SOURCE: National Center for Health Statistics, National Vital Statistics System, Mortality.

Figure 2. Age-adjusted drug overdose death rates, by race and Hispanic origin: United States, 2019

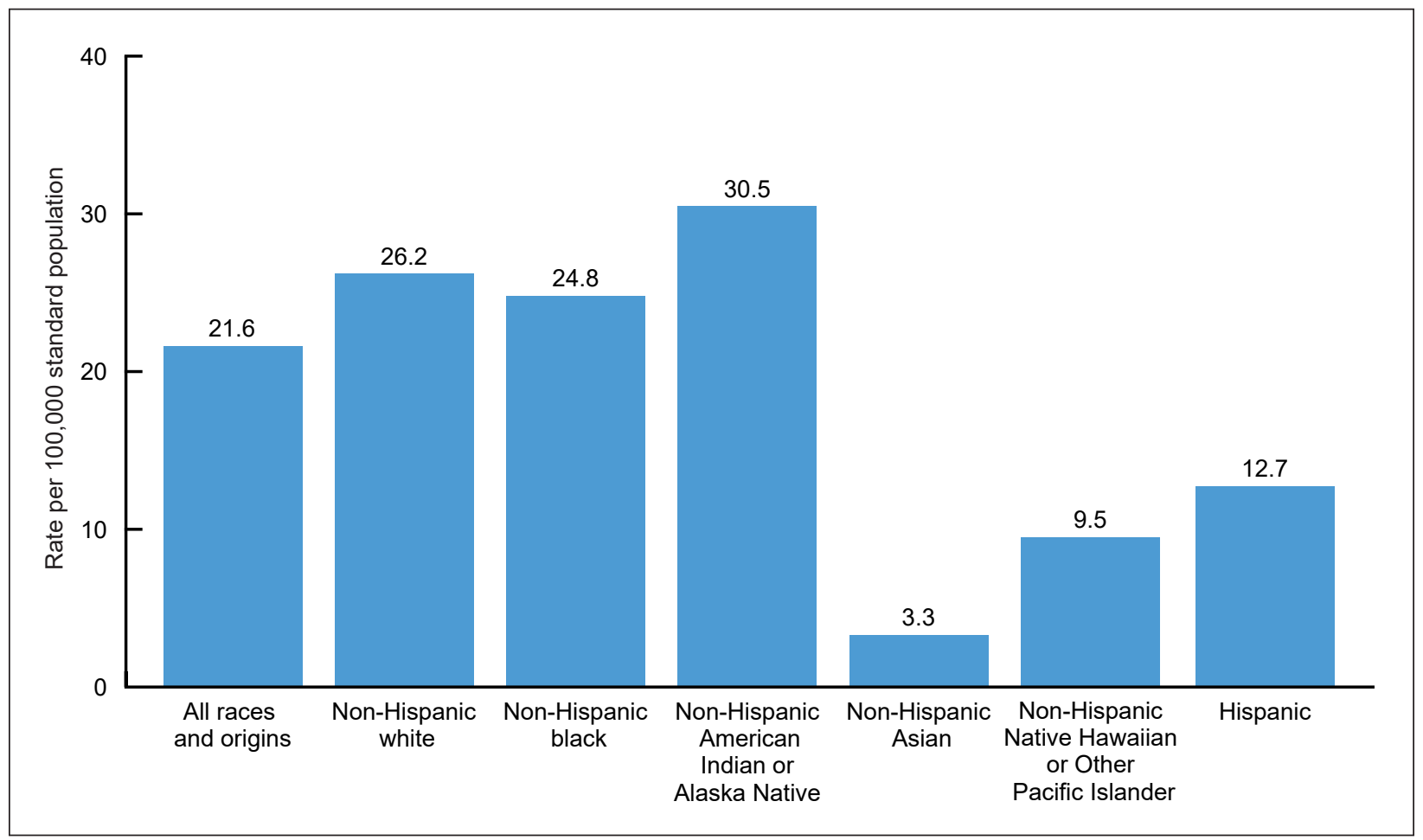

NOTES: Drug overdose deaths were identified using International Classification of Diseases, 10th Revision underlying cause-of-death codes X40-X44, X60-X64, $\mathrm{X} 85$, and $\mathrm{Y} 10-\mathrm{Y} 14$. Age-adjusted death rates were calculated using the direct method and the $2000 \mathrm{U}$.S. standard population.

SOURCE: National Center for Health Statistics, National Vital Statistics System, Mortality. 
Table. Number and age-adjusted rates of drug overdose deaths, by state: United States, 2019

\begin{tabular}{|c|c|c|}
\hline Area & Number & Deaths per 100,000 \\
\hline United States & 70,630 & 21.6 \\
\hline Alabama & 768 & 16.3 \\
\hline Alaska & 132 & 17.8 \\
\hline Arizona & 1,907 & 26.8 \\
\hline Arkansas & 388 & 13.5 \\
\hline California & 6,198 & 15.0 \\
\hline Colorado & 1,079 & 18.0 \\
\hline Connecticut & 1,214 & 34.7 \\
\hline Delaware & 435 & 48.0 \\
\hline District of Columbia & 311 & 43.2 \\
\hline Florida & 5,268 & 25.5 \\
\hline Georgia & 1,408 & 13.1 \\
\hline Hawaii & 242 & 15.9 \\
\hline Idaho & 265 & 15.1 \\
\hline Illinois & 2,790 & 21.9 \\
\hline Indiana & 1,699 & 26.6 \\
\hline lowa & 352 & 11.5 \\
\hline Kansas & 403 & 14.3 \\
\hline Kentucky & 1,380 & 32.5 \\
\hline Louisiana & 1,267 & 28.3 \\
\hline Maine & 371 & 29.9 \\
\hline Maryland & 2,369 & 38.2 \\
\hline Massachusetts & 2,210 & 32.1 \\
\hline Michigan & 2,385 & 24.4 \\
\hline Minnesota & 792 & 14.2 \\
\hline Mississippi & 394 & 13.6 \\
\hline Missouri & 1,583 & 26.9 \\
\hline Montana & 143 & 14.1 \\
\hline Nebraska & 161 & 8.7 \\
\hline Nevada & 647 & 20.1 \\
\hline New Hampshire & 407 & 32.0 \\
\hline New Jersey & 2,805 & 31.7 \\
\hline New Mexico & 599 & 30.2 \\
\hline New York & 3,617 & 18.2 \\
\hline North Carolina & 2,266 & 22.3 \\
\hline North Dakota & 82 & 11.4 \\
\hline Ohio & 4,251 & 38.3 \\
\hline Oklahoma & 645 & 16.7 \\
\hline Oregon & 615 & 14.0 \\
\hline Pennsylvania & 4,377 & 35.6 \\
\hline Rhode Island & 307 & 29.5 \\
\hline South Carolina & 1,127 & 22.7 \\
\hline South Dakota & 86 & 10.5 \\
\hline Tennessee & 2,089 & 31.2 \\
\hline Texas & 3,136 & 10.8 \\
\hline Utah & 571 & 18.9 \\
\hline Vermont & 133 & 23.8 \\
\hline Virginia & 1,547 & 18.3 \\
\hline Washington & 1,259 & 15.8 \\
\hline West Virginia & 870 & 52.8 \\
\hline Wisconsin & 1,201 & 21.1 \\
\hline Wyoming & 79 & 14.1 \\
\hline
\end{tabular}

NOTES: Drug overdose deaths were identified using International Classification of Diseases, 10 th

Revision underlying cause-of-death codes X40-X44, X60-X64, X85, and Y10-Y14. Age-adjusted death rates were calculated using the direct method and the 2000 U.S. standard population.

SOURCE: National Center for Health Statistics, National Vital Statistics System, Mortality. 